\title{
Abbreviations Used
}

$\mathrm{CW}$ Joyce, James. The Critical Writings of James Joyce, eds.

Ellsworth Mason and Richard Ellmann. New York: Viking Compass, 1964 .

D Joyce, James. Dubliners. New York: Penguin Books, 1976.

E Joyce, James. Exiles. New York: Viking Compass, I96r.

JJI Ellmann, Richard. James Joyce. New York: Oxford Univ. Press, I959.

JJII Ellmann, Richard. James Joyce. New York: Oxford Univ. Press, 1982.

Letters Joyce, James. Vol. I, ed. Stuart Gilbert.

I II III New York: Viking Press, I957. Vols. II and III, ed. Richard Ellmann. New York: Viking Press, 1966.

P Joyce, James. A Portrait of the Artist as a Young Man. New York: Penguin Books, 1976.

SH Joyce, James. Stephen Hero, eds. Theodore Spencer, John J. Slocum and Herbert Cahoon. New York: New Directions, 1944-1963.

SL Joyce, James. Selected Letters, ed. Richard Ellmann. New York: Viking Press, 1975.

$U$ Joyce, James. Ulysses, ed. Hans Walter Gabler, et al. New York: Random House, 1986. 
THIS PAGE INTENTIONALLY LEFT BLANK 